\title{
Effect of viscosity on homogeneous-heterogeneous flow regime transition in bubble columns
}

\author{
M.C. Ruzicka ${ }^{\mathrm{a}, *}$, J. Drahoš ${ }^{\mathrm{a}}$, P.C. Mena ${ }^{\mathrm{b}}$, J.A. Teixeira ${ }^{\mathrm{c}}$ \\ ${ }^{a}$ Institute of Chemical Process Fundamentals, Czech Academy of Sciences, Rozvojova 135, 16502 Prague, Czech Republic \\ ${ }^{\mathrm{b}}$ Department of Chemical Engineering, Faculty of Engineering, University of Porto, 4200-465 Porto, Portugal \\ ${ }^{\mathrm{c}}$ Centre of Biological Engineering-IBQF, University of Minho, 4710-057 Braga, Portugal
}

\begin{abstract}
Experiments were performed in a cylindrical $0.14 \mathrm{~m}$ diameter bubble column with a metal perforated plate. Air and aqueous solutions of glycerol with viscosity $1-22 \mathrm{mPa}$ sere the phases. Gas holdup was measured and plotted against the gas flow rate. The critical point where the homogeneous-heterogeneous regime transition begins was determined by the drift-flux plot of the primary data. The homogeneous regime stability was expressed by the critical values of the gas holdup and gas flow rate. The results show that moderate viscosity (3-22 $\mathrm{mPa} \mathrm{s}$ ) destabilizes the homogeneous regime and advance the transition. The results indicate that low viscosity (1-3 mPa s) could stabilize the homogeneous regime. The destabilizing effect of the column height proved previously for air-water system applies also to viscous batches.
\end{abstract}

(C) 2003 Elsevier B.V. All rights reserved.

Keywords: Bubble column; Flow regime; Stability; Viscosity

\section{Introduction}

Two basic flow regimes in bubble columns are widely recognized: homogeneous and heterogeneous [1-3]. In the homogeneous regime, the bubble concentration (voidage, gas holdup) and the gas and liquid velocities are uniformly distributed within the column, when the long-term average is taken. The bubbles rise almost vertically at a velocity lower than the terminal velocity due to the hindrance effect. There are no large-scale motions (circulations) in the liquid. In the heterogeneous regime, strong circulations develop and cause that the holdup and velocities display pronounced radial profiles. The bubble rise velocity is enhanced by the circulations. These two regimes differ one another in hydrodynamic and transport characteristics, as well as in their suitability for a particular technological process.

Usually, monodisperse bubbles are observed in the homogeneous regime while polydisperse in the heterogeneous regime, where vigorous coalescence and breakup typically occur. The bubble polydispersity is often made responsible for the breakdown of the uniformity, but even with equal-size bubbles, the homogeneous regime will break at a critical holdup by disturbances, buoyant bubble clusters, sponta-

\footnotetext{
* Corresponding author. Tel.: +420-2-20390299; fax: +420-2-20920661.

E-mail address: ruzicka@icpf.cas.cz (M.C. Ruzicka).
}

neously formed due to hydrodynamic bubble-bubble interactions. The clusters play virtually the same role as the big bubbles in a polydisperse system.

Depending on the gas distributor, column dimensions, and properties of the phases, both regimes can be obtained in the same equipment by varying the gas input [4]. The homogeneous regime occurs at low gas flow, and loses stability and gradually turns into the heterogeneous regime at higher gas flow. Also, under certain conditions (e.g. plates with big and sparse orifices), the homogeneous regime cannot be generated in the column, and the heterogeneous regime then exists in the column at all gas flows. This so called 'pure' heterogeneous regime is considered to be identical with the heterogeneous regime resulting from the transition.

The regimes can be discriminated by their gas holdup-gas flow rate graphs, $e(q)$. The steady holdup in either regime is given by the formula $e=q / u$ (mass conservation of gas phase), where $q$ is the superficial gas velocity and $u$ the mean gas phase rise velocity. If the bubbles travelled unaffected at their terminal velocity $u_{0}$, the holdup would increase linearly with the gas flow rate, $e=q / u_{0} \sim q$. Thus the deviations from the linearity are caused by the hydrodynamic phase coupling. In the homogeneous regime, the hindrance progressively reduces the bubble velocity with increasing holdup (e.g. $\left.u=u_{0}(1-e)^{m}\right)$, which results in a progressive increase of the holdup with the gas flow, a convex graph $e(q)$, see Fig. 1. In the heterogeneous regime, 


\begin{tabular}{|c|c|}
\hline \multicolumn{2}{|c|}{ Nomenclature } \\
\hline$a$ & bubble drift coefficient $(-)$ \\
\hline$c$ & parameter of Eq. (8) (-) \\
\hline$d$ & bubble diameter $(\mathrm{m})$ \\
\hline$D$ & column diameter $(\mathrm{m})$ \\
\hline$e$ & $\begin{array}{l}\text { gas holdup (porosity, voidage, volumetric } \\
\text { bubble concentration) (-) }\end{array}$ \\
\hline$g$ & gravity $\left(\mathrm{m} / \mathrm{s}^{2}\right)$ \\
\hline$H$ & $\begin{array}{l}\text { column height (clear liquid height, } \\
\text { unaerated liquid level) (m) }\end{array}$ \\
\hline$j$ & drift-flux (m/s) \\
\hline$k_{1}, k_{2}$ & parameters of Eq. (8) (-) \\
\hline$q$ & $\begin{array}{l}\text { gas flow rate (linear gas velocity, specific } \\
\text { gas flow, superficial gas velocity) }(\mathrm{m} / \mathrm{s})\end{array}$ \\
\hline$R$ & correlation coefficient (-) \\
\hline$t$ & bubble retention time (s) \\
\hline$u$ & $\begin{array}{l}\text { mean gas phase rise velocity (bubble swarm } \\
\text { velocity, bubble slip velocity) }(\mathrm{m} / \mathrm{s})\end{array}$ \\
\hline$u_{0}$ & $\begin{array}{l}\text { terminal bubble velocity (single bubble } \\
\text { velocity, isolated bubble velocity) }(\mathrm{m} / \mathrm{s})\end{array}$ \\
\hline$v$ & gas velocity inside orifice $(\mathrm{m} / \mathrm{s})$ \\
\hline We & orifice Weber number (-) \\
\hline \multicolumn{2}{|c|}{ Greek letters } \\
\hline$\gamma$ & liquid kinematic viscosity $\left(\mathrm{m}^{2} / \mathrm{s}\right)$ \\
\hline$\kappa$ & hydrodynamic bubble diffusivity $\left(\mathrm{m}^{2} / \mathrm{s}\right)$ \\
\hline$\mu$ & liquid dynamic viscosity (mPa s) \\
\hline$\rho$ & density $\left(\mathrm{kg} / \mathrm{m}^{3}\right)$ \\
\hline$\sigma$ & $\begin{array}{l}\text { interfacial surface tension } \\
(\approx \text { liquid surface tension })(\mathrm{N} / \mathrm{m})\end{array}$ \\
\hline$\varphi$ & relative free plate area $(-)$ \\
\hline \multicolumn{2}{|c|}{ Subscripts } \\
\hline $\mathrm{c}$ & $\begin{array}{l}\text { critical value (end of homogeneous regime, } \\
\text { beginning of regime transition) }\end{array}$ \\
\hline $\mathrm{g}$ & gas \\
\hline 1 & liquid \\
\hline $\mathrm{s}$ & $\begin{array}{l}\text { stable plate operation regime (beginning of } \\
\text { homogeneous regime) }\end{array}$ \\
\hline
\end{tabular}

the circulations progressively enhance the bubble velocity (e.g. $u=u_{0}+$ const. $\times q$ ), namely in the central core of the column where most of the gas passes through, which results in a progressive decrease of the holdup with the gas flow, a concave graph $e(q)$, see Fig. 1. Note that the mean bubble velocity $u$ relates to the bubble retention time $t$ by $u=H / t$, where $H$ is the column height, giving a linear relation $e \sim t$.

The regime transition has been studied and several models suggested, e.g. [5] and references therein. Despite these efforts, many basic questions about the effect of important operational parameters and the system properties on the transition remain unanswered. These gaps in our knowledge limit our ability to design and control gas-liquid contacting and reacting systems. gas holdup $e[-]$

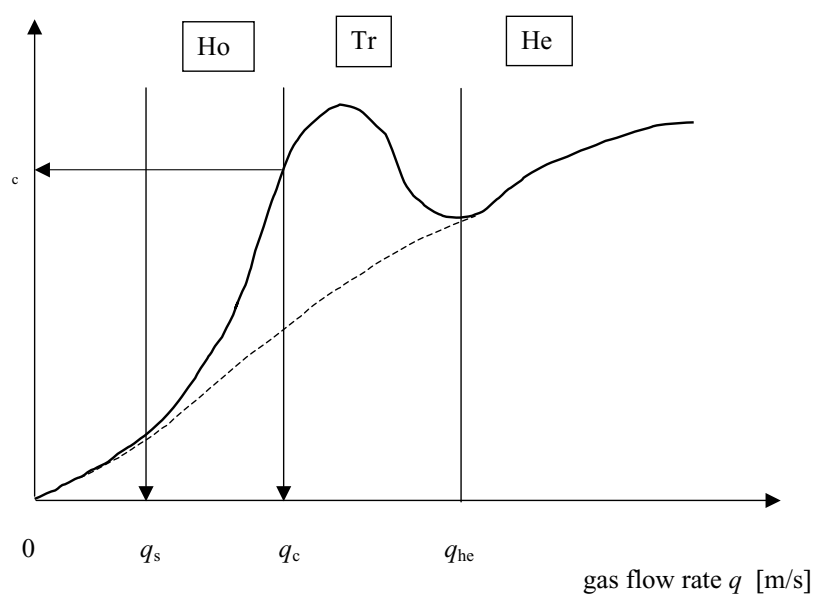

Fig. 1. Definition sketch of flow regimes in bubble column. Full line: Ho-homogeneous regime; $\mathrm{Tr}$-transition regime; He-heterogeneous regime; $q_{\mathrm{s}}$-stable plate operation regime, beginning of homogeneous regime; $q_{\mathrm{c}}$-critical point, end of homogeneous regime, beginning of regime transition; $q_{\mathrm{he}}$ - end of regime transition, beginning of heterogeneous regime; $e_{\mathrm{c}}-$ critical voidage. Broken line: pure heterogeneous regime.

There are numerous results scattered in literature about the effect of the liquid viscosity on the gas holdup in the heterogeneous regime. Generally, it is reported that the holdup decreases with increasing viscosity. This is attributed to the presence of large population of big and fast bubbles with short retention time in the bed $[1,2,4,6,7]$. Not only the viscous media are favourable for formation of big bubbles directly at the gas distributor $[1,2,8]$, but also they promote bubble coalescence $[2,4,8-10]$ and suppress bubble breakup in the bed $[9,11]$. The decrease of holdup is reflected by various correlations containing the viscosity effect. They are usually of the form $e \sim \mu^{n}$ with different values of $n$ : -0.053 and -0.16 [2], -0.05 [1], -0.22 and others [12].

On the other hand, there are studies reporting controversial effects of the viscosity $[1,2,11,13]$. Indeed, both increase and decrease of the heterogeneous gas holdup have been observed $[8,12,14-17]$. An increase was found at low viscosity $\mu<3$, a decrease at moderate viscosity $\mu=3-11$, and a roughly constant holdup at higher viscosity $\mu>11$ [14]. To reconcile this ambiguity, the viscosity was supposed to play a dual role [14]. At a low viscosity, the larger drag forces reduce the bubble rise velocity and thus cause an increase in holdup. At the same time, these forces are not strong enough to promote the coalescence. At a higher viscosity, the tendency to coalescence and polydispersity prevails over the drag reduction and the uniformity is broken by big bubbles. This explanation was supported also by other authors $[8,11,13,15,16]$.

In highly viscous batches, the bubble polydispersity turns into a virtual bidispersity. Here, the bubble population dynamics becomes important. Roughly bimodal population was observed of small (less than $1 \mathrm{~mm}$ ) and large (above 
$20 \mathrm{~mm}$ ) bubbles, with the former formed from the latter preferably near the plate and at the liquid surface [18]. Despite that the small bubbles received only less than $1 \%$ of the total gas input, they accumulated due to very low rise velocities and represented substantial portion of the total holdup, up to $50 \%$. The aeration time needed to establish the equilibrium holdup amounted tenth of minutes. Expectedly, the small bubble holdup increased with both the gas flow rate and the viscosity. It was found too, that the temporal increase of the holdup due to the small bubble accumulation obeys a first-order kinetics [19]. The bed establishment took more than an hour and the small bubble holdup was up to $60 \%$ of the total holdup. A further study showed that the bed establishment time is virtually zero in lower viscosity liquids, $\mu<30$, say, where the bubble population dynamics can be neglected [8]. At higher viscosity, $\mu>30$, say, however, the formation and accumulation of the small bubbles is substantial and results in further increase of the total holdup with increasing viscosity, instead of the levelling at a constant value as reported earlier in [14]. The overall viscosity effect on the heterogeneous holdup can be summarized as follows: the holdup increases for $\mu<3$, decreases for $3<\mu<30$, and increases again for $\mu>30$, where these numerical values are tentative. It should also be pointed out, that the adverse effect of the viscosity on the holdup can be compensated by addition of various surfactants that tend to increase the holdup, e.g. alcohols and inorganic salts [4].

There are scarce results on the effect of the liquid viscosity on the homogeneous regime and its stability. Generally, an adverse effect is expected due to deterioration of the uniformity by the strong variation in bubble sizes, caused mainly by the coalescence $[1,2,11]$. Experience with bubble columns indicates that the homogeneous regime is much more sensitive to the properties of the phases than the heterogeneous regime $[2,16]$. Available experiments show that the homogeneous holdup decreases with increasing viscosity $[4,8,16]$. Further, it was found that the homogeneous regime can be completely suppressed in sufficiently viscous liquids, roughly at $\mu>8$, say, and the heterogeneous regime occurs even with 'homogeneous plates' (fine and closely spaced orifices) at low gas flow $[4,8]$. The flow regime in viscous batches is thus virtually independent on the geometry of the gas distributor, which should be kept in mind while designing real equipments.

The observed decrease of the gas holdup with increasing viscosity suggests that also the homogeneous regime stability will be reduced $[4,8,11]$. However, this only is a conjecture that must be proved experimentally: a parameter directly related to the stability must be evaluated and plotted against the viscosity. This parameter can be, for instance, the critical holdup $e_{\mathrm{c}}$ or the critical gas flow rate $q_{\mathrm{c}}$.

There are two studies concerning the critical values, both based on simple modelling concepts and involving correlations. First, some previous results on the transition from bubble to plug flow in vertical pipes were adopted for bubble columns [20]. It was assumed that the transition occurs at a fixed value of the critical holdup $e_{\mathrm{c}}=0.13$ (which is rather unrealistic) and a simple expression was obtained for the critical gas flow $q_{\mathrm{c}}=0.188 u_{0}$ (zero liquid throughput). The viscosity effect comes through the dependence of $u_{0}$ on $\mu$, obtained from correlations. The prediction was compared with a little success with data from [21]. Second, the model from [22] was combined in [11] with dimension analysis approach to various gas holdup data collected from literature. An empirical exponential formula was chosen to describe the viscosity effect by a correlation, and a decrease was found of the critical holdup $e_{\mathrm{c}} \sim \exp \left(-\right.$ const. $\left.\times \mu^{0.5}\right)$ [11]. It was not specified how consistent the data of different origin were and how the critical point was evaluated. In our best knowledge, detailed and consistent experiments aimed at the viscosity effect on the stability have not been done yet.

There are also two theoretical studies dealing with the homogeneous regime stability. First, a linear stability analysis was performed in $[23,24]$ on relatively simple $2 \mathrm{D}$ bubbly flow equations of motion and a stability criterion for the transition was derived. Unfortunately, viscosity disappeared along the derivations due to considering inviscid boundary conditions, and, therefore, it does not enter the final criterion. Second, a general stability concept was developed for uniform dispersed layers based on the analogy with thermal convection [25]. The homogeneous-heterogeneous regime transition in bubble columns was considered to be physically similar to the Rayleigh-Benard instability of thermal layers. The Rayleigh number was introduced for bubbly layers, which gives a stability criterion in terms of the critical holdup. The criterion predicts a stabilizing effect of the viscosity on the homogeneous regime with a linear increase of critical holdup with viscosity $e_{\mathrm{c}} \sim \mu$, which contradicts the general expectation. This prediction has not yet been proved by experiments.

This study presents experimental results on the effect of the liquid viscosity on the stability of the homogeneous flow regime. Detailed measurements are performed and the critical values of the gas holdup and the gas flow rate are carefully evaluated. The results basically prove that the moderate viscosity destabilizes the homogeneous regime and advances the transition.

\section{Experiments and data evaluation}

A cylindrical plexiglas $0.14 \mathrm{~m}$ diameter bubble column was equipped with a $3 \mathrm{~mm}$ thick brass perforated plate with $0.5 \mathrm{~mm}$ diameter orifices with $10 \mathrm{~mm}$ pitch and relative free area $\varphi=0.002$. Plates of this kind produce the homogeneous regime and its transition to the heterogeneous regime [26]. Compressed air from the laboratory lines was used as the gas phase. Aqueous solutions of glycerol in tap water were used as the liquid phase. Glycerol was chosen as the viscosity providing agent, because it has a simple Newtonian rheology and, as a non-polar solute, it has a negligible surface activity [16]. The following eight values of viscosity 
were employed: $\mu=1$ (water), 1.6, 2.1, 3.8, 5.4, 6, 8.5, and $22 \mathrm{mPa}$. The ungased liquid height took three different values $H=0.2,0.4$, and $0.8 \mathrm{~m}$. The dependence of the holdup $e$ on the gas flow rate $q$ was measured. The gas flow was read from rotametres and the holdup was determined from the bed expansion. Each experimental run was repeated three-times and the holdup values were averaged (relative error less than $5 \%$ ).

The homogeneous regime is limited from below by the point of the stable plate operation regime (index $s$ ), and from above by the critical point (index $c$ ), see Fig. 1. To produce a uniform bubble bed, the plate operation must be independent of pressure fluctuations on both the gas and liquid sides, and all orifices must work steadily $[26,27]$. This is expected to happen when the orifice Weber number is larger than 2 [28]:

$W e \equiv \frac{\rho_{\mathrm{g}} \mathrm{d} v^{2}}{\sigma}=\frac{\rho_{\mathrm{g}} \mathrm{d} q^{2}}{\sigma \varphi^{2}}>2$.

The condition $W e=2$ thus determines the value of $q_{\mathrm{s}}$. For our system, according to Eq. (1), the homogeneous regime should begin at $q_{\mathrm{s}} \approx 0.03 \mathrm{~m} / \mathrm{s}$, which seems to be rather high. Note, however, that this theoretical estimate is only one of many and must be supported with visual observation of the actual plate behaviour in the particular experimental equipment. The critical point $\left[q_{\mathrm{c}}, e_{\mathrm{c}}\right]$ where the homogeneous regime loses stability and the transition begins was determined from the drift-flux plot $j=j(e)$ [29]. At the critical point, the experimental data $j=(1-e) q$ depart from the theoretical curve for the homogeneous regime $j=e(1-e) u$. The values of $q_{\mathrm{c}}$ and $e_{\mathrm{c}}$ were taken as the measures of the homogeneous regime stability. The bubble slip velocity $u$ was calculated by the formula derived for the homogeneous regime [30]:

$u(e)=u_{0}\left(1-\frac{a e}{1-e}\right)$,

which gives results comparable with other expressions, e.g. [31]. The values of the bubble terminal velocity $u_{0}$ and the bubble drift coefficient $a$ can be extracted from the experimental data $e(q)$ using the relation $e=q / u$ and linearizing Eq. (2):

$\frac{q}{e}=\left(u_{0}\right)-\left(a \cdot u_{0}\right) \frac{e}{1-e}$.

$u_{0}$ and $a$ can also be found by trial and error to obtain the best fit of the data in the drift-flux plot.

\section{Results and discussion}

\subsection{Gas holdup}

For $\mu>3$, say, the primary experimental data $e(q)$ displayed in Fig. 2 witness a considerable reduction of the gas holdup as a result of increasing liquid viscosity, which is in agreement with the expectation. The character of the $e-q$
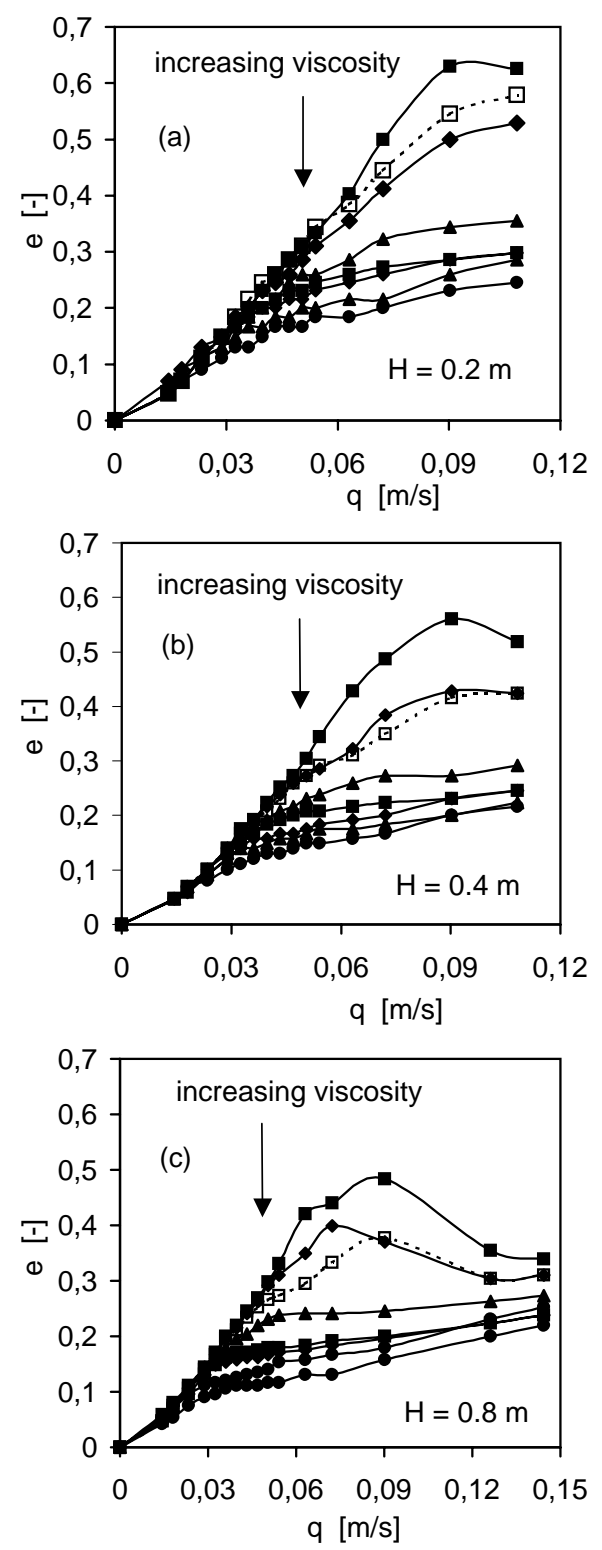

Fig. 2. Primary data: gas holdup $e$ versus gas flow rate $q$. Increasing liquid viscosity: $\mu=1$ (broken line), $1.6,2.1,3.8,5.4,6,8.5,22 \mathrm{mPas}$. Column height: (a) $H=0.2 \mathrm{~m}$; (b) $H=0.4 \mathrm{~m}$; (c) $H=0.8 \mathrm{~m}$.

dependence changes smoothly from the typical transition curves with expressive maxima obtained at low viscosity, to rather monotonous lines of the heterogeneous regime found at higher viscosity (cf. Fig. 1). The results conform the empirical rule suggested by Zahradník et al. [4], that the homogeneous regime cannot exist above a certain value of the viscosity, $\mu>8$, say. This 'rule' was based only on a visual inspection of the flow pattern in the column and on the character of the $e-q$ graph, but not on the critical values.

For $\mu<3$, say, the data in Fig. 2 indicate a holdup increase with the viscosity, which is not expected for the homogeneous regime: one or two full lines with $\mu=1.6$ and 2.1 are above the broken line with $\mu=1$. It suggests, that 

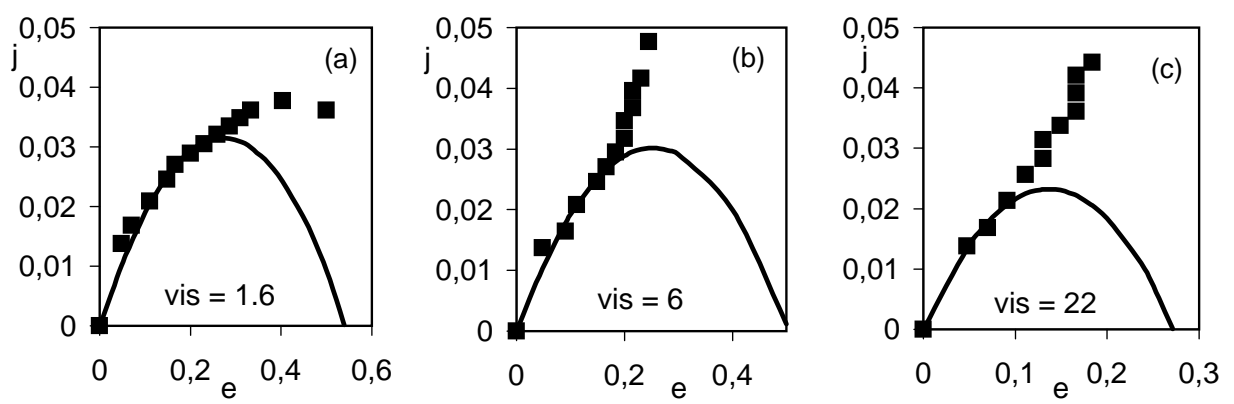

Fig. 3. Drift-flux plot: drift-flux $j$ versus gas holdup $e$. Experimental data (disconnected marks). Theoretical curve for homogeneous regime (parabolic line): (a) $\mu=1.6, e_{\mathrm{c}}=0.26, q_{\mathrm{c}}=0.043$; (b) $\mu=6, e_{\mathrm{c}}=0.17, q_{\mathrm{c}}=0.032$; (c) $\mu=22, e_{\mathrm{c}}=0.09, q_{\mathrm{c}}=0.023$. Column height: $H=0.2 \mathrm{~m}$.

the dual role of the viscosity observed in the heterogeneous regime may apply also to the homogeneous regime. It also suggests, that a small viscosity could stabilize uniform bubbly layers, as predicted by the theory of Ruzicka and Thomas [25]. There are not enough data in the present study to be more conclusive and further measurements focused on the range $\mu=1-3$, say, are necessary for the definite answer.

\subsection{Drift-flux plot}

Three examples of the Wallis' plot for the critical point determination are shown in Fig. 3. These graphs clearly show that the data depart from the parabola earlier at higher viscosity and give lower values of the critical holdup.

At low gas flow (holdup), the data also lie on the parabola despite the fact that the uniform bubbling condition by Eq. (1) is not satisfied-the homogeneous regime would not be fully established. It suggests that Eq. (1) may not be very accurate and/or that the long-term uniformity assumed in the Wallis' theory can exist in bubble columns even below $q_{\mathrm{s}}$ despite that not all orifices work at a given instant.

The drift-flux plot can give values of $q_{\mathrm{c}}$ that are smaller than $q_{\mathrm{s}}(\approx 0.03 \mathrm{~m} / \mathrm{s}$, in our case): the homogeneous regime breaks even before its appears, see Fig. 1. Physically, this paradox means that the homogeneous regime is absent because it cannot develop. The condition $q_{\mathrm{s}}=q_{\mathrm{c}}$ enables to determine the limiting viscosity above which the bubble bed is not uniform. For instance, at $\mu=6$ and $8.5 \mathrm{mPa}$, the values of $q_{\mathrm{c}}$ are 0.032 and $0.029 \mathrm{~m} / \mathrm{s}(H=0.2 \mathrm{~m})$, which corresponds to the above mentioned Zahradník's empirical limiting viscosity $\approx 8 \mathrm{mPa}$.

\subsection{Critical values}

The critical values of the holdup and gas flow rate measure the homogeneous regime stability and are displayed in Fig. 4. The data show a general statistically decreasing trend that proves the destabilizing effect of the viscosity. Also, the results prove the conjecture that a decrease in the holdup $(e)$ corresponds to a decrease in the critical holdup $\left(e_{\mathrm{c}}\right)$, cf. Fig. 2 and Fig. 4. The critical data allow for an overall empirical power-law fit:

$e_{\mathrm{c}}=0.28 \mu^{-0.37}$,
$q_{\mathrm{c}}=0.048 \mu^{-0.24}$,

where the numerical values represent the mean over the three column heights employed, see Fig. 5a. These empirical correlation are to quantify the trend observed in our narrow range of data, rather than to be used for design and scale-up of real equipment. To recover the effect of the column dimensions $H$ and $D$ on $e_{\mathrm{c}}$, the value 0.28 in (4) should be replaced with the formula $(0.22-0.17 D) H^{-(0.09+0.38 D)}$ obtained previously for the air-water system [30]. Alternatively, a general exponential fit of the data is possible too (see Fig. 5b):

$e_{\mathrm{c}}=0.23 \exp (-0.054 \mu)$.

Finally, the data can also be fitted with a particular exponential formula suggested in [11] for design and scale-up (see Fig. 5c):

$e_{\mathrm{c}}=0.31 \exp \left(-0.33 \mu^{0.5}\right)$.

It is noteworthy that the unexpected slight increase of the holdup with the viscosity at $\mu<3$ found in Fig. 2 results in a stabilizing effect in Fig. $4 \mathrm{a}$ and $\mathrm{c}$, where the blank data points with $\mu=1$ are below the next points with $\mu=1.6$. The stabilization is especially remarkable in Fig. 4c. The prediction of the Ruzicka and Thomas theory [25] is shown by the full lines in Fig. 4a, c, and e. Their formula for the critical holdup reads

$e_{\mathrm{c}}=\frac{\gamma \kappa}{g}\left[\frac{k_{1}}{H^{3}}+\frac{k_{2}}{H^{3-c} D^{c}}\right]$,

where $\gamma$ is the kinematic viscosity of the bubbly mixture, $\kappa$ the hydrodynamic diffusivity of bubbles, $g$ the gravity and $k_{1}, k_{2}$ and $c$ the empirical parameters. Upon substituting [25] $\gamma=10^{-3} \mu / \rho_{1}$ (note that $\mu$ is in mPas), $\kappa=10^{-3}, g=$ $9.81, k_{1}=10^{5}, k_{2}=6.7 \times 10^{6}, c=2.84$, Eq. (8) gives the following linear relations between the critical holdup and viscosity, which are displayed in Fig. 4:

$e_{\mathrm{c}}=0.236 \mu, \quad H=0.2 \mathrm{~m}$, 

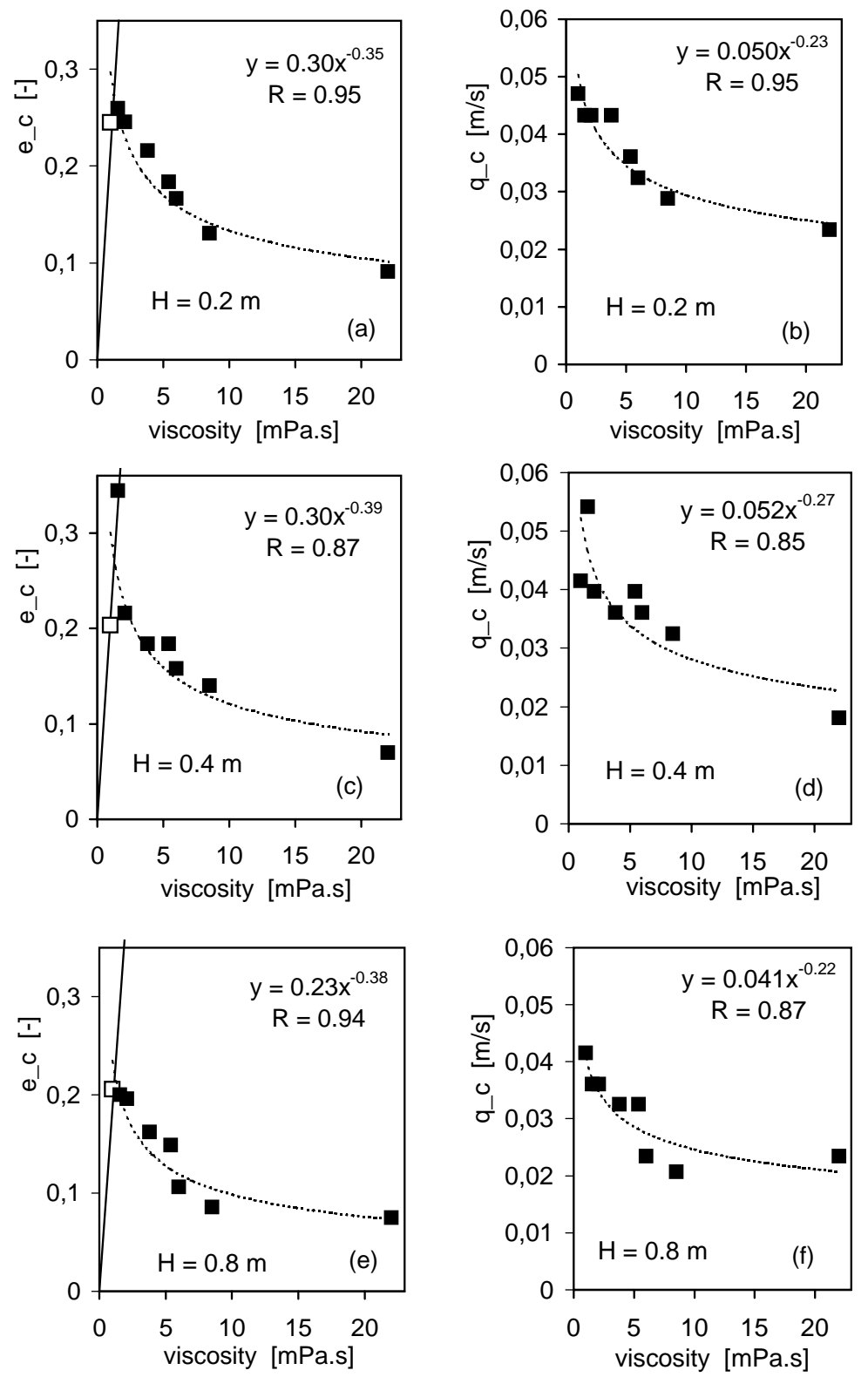

Fig. 4. Effect of viscosity $\mu$ on critical values of holdup $e_{\mathrm{c}}$ and gas flow rate $q_{\mathrm{c}}$. Experimental data (marks). Power-law fit of data (dotted lines). Prediction of $e_{\mathrm{c}}$ by Eq. (9) from Ruzicka and Thomas theory [25] (full lines in a, c, e). Lowest viscosity point $\mu=1 \mathrm{mPa} \mathrm{s}$ (blank marks in a, c, e). Column height: (a, b) $H=0.2 \mathrm{~m}$; (c, d) $H=0.4 \mathrm{~m}$; (e, f) $H=0.8 \mathrm{~m}$.
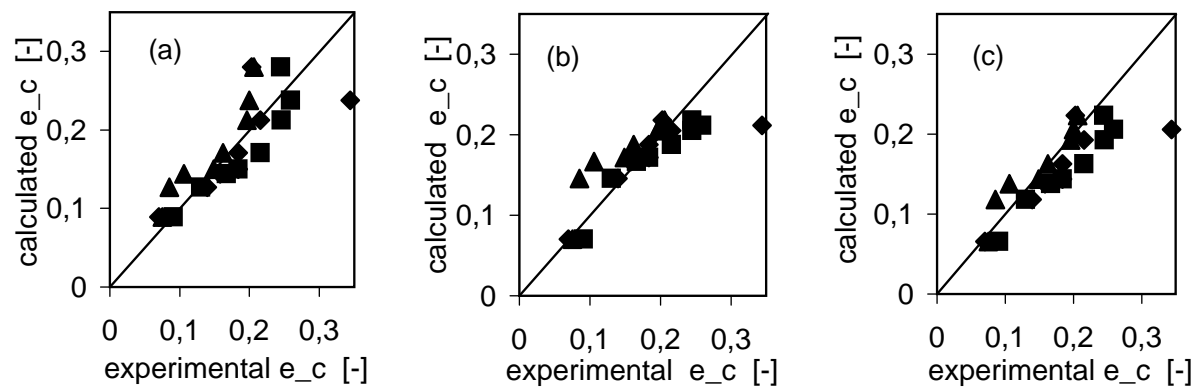

Fig. 5. Various correlations for critical voidage $e_{\mathrm{c}}$ : (a) Eq. (4), (b) Eq. (6), (c) Eq. (7). Column height: $H=0.2 \mathrm{~m}(\boldsymbol{\square}) ; H=0.4 \mathrm{~m}(\bullet) ; H=0.8 \mathrm{~m}(\boldsymbol{\Delta})$. 


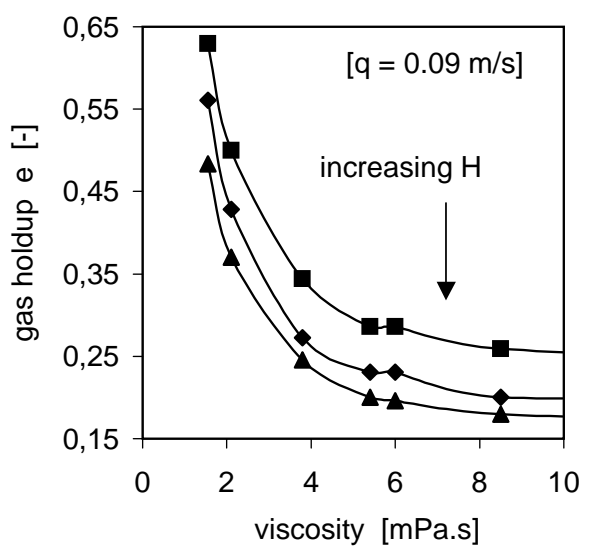

Fig. 6. Effect of column height $H$ on gas holdup $e$ in viscous batches. Holdup (connected marks) shows power-law decrease with viscosity $e=p \mu^{-r}$ with values $[p, r, R]=[0.63,0.39,0.93],[0.54,0.40,0.89]$, and $[0.48,0.43,0.93]$ for column heights $H=0.2,0.4$, and $0.8 \mathrm{~m}$.

$e_{\mathrm{c}}=0.211 \mu, \quad H=0.4 \mathrm{~m}$,

$e_{\mathrm{c}}=0.188 \mu, \quad H=0.8 \mathrm{~m}$.

The first two points in Fig. 4c follow the line (9b) well. However, this finding has only an indicative value since there are not enough data within this range. Nevertheless, the stabilizing effect of a small viscosity may well be anticipated (new experiments are currently under way).

\subsection{Effect of column height}

Fig. 6 contains the holdup data for three different heights $H=0.2,0.4$, and $0.8 \mathrm{~m}$, at a fixed value of the gas flow rate $(q=0.09 \mathrm{~m} / \mathrm{s})$ that is higher than the critical values (see Fig. $4 \mathrm{~b}, \mathrm{~d}$ and $\mathrm{f}$ ). The holdup decreases with increasing the column height, which is in full accord with our previous results on the destabilizing effect of the column size obtained for air-water systems [30]. It follows, that the unfavourable effect of the column height on the holdup applies also to viscous batches.

\section{Conclusions}

The adverse effect of the liquid viscosity on the homogeneous regime stability for aqueous glycerol solutions of moderate viscosity was found experimentally. Both the holdup and its critical value decrease with increasing viscosity for $\mu=3-22 \mathrm{mPas}$. This is in accord with the previous expectation. On the other hand, the measurements also indicate that there is a narrow viscosity range $\mu=1-3 \mathrm{mPa}$ s where the viscosity could stabilize the homogeneous regime as predicted by the theory of Ruzicka and Thomas [25], which is in contrast with the common belief.

\section{Acknowledgements}

Support by GACR (Grant No. 104/01/0547) is gratefully acknowledged. P.C. Mena thanks the EC for the Marie Curie Training Site Fellowship at the Institute of Chemical Process Fundamentals, Prague, CZ (Contract Number HPMT-CT-2000-00074).

\section{References}

[1] W.D. Deckwer, Bubble Column Reactors, Wiley, Chichester, 1992.

[2] F. Kaštánek, J. Zahradník, J. Kratochvíl, J. Čermák, Chemical Reactors for Gas-Liquid Systems, Ellis Horwood, Chichester, UK, 1993.

[3] O. Molerus, Principles of Flow in Disperse Systems, Chapman \& Hall, London, 1993.

[4] J. Zahradník, M. Fialová, M. Ruzicka, J. Drahoš, F. Kaštánek, N.H. Thomas, Duality of the gas-liquid flow regimes in bubble column reactors, Chem. Eng. Sci. 52 (1997) 3811-3826.

[5] M.C. Ruzicka, J. Zahradník, J. Drahoš, N.H. Thomas, Homogeneousheterogeneous regime transition in bubble columns, Chem. Eng. Sci. 56 (2001) 4609-4626.

[6] W.D. Deckwer, A. Schumpe, Improved tools for bubble column reactor design and scale-up, Chem. Eng. Sci. 48 (1993) 889-911.

[7] M.V. Kantak, R.P. Hesketh, B.G. Kelkar, Effect of gas and liquid properties on gas phase dispersion in bubble columns, Chem. Eng. J. 59 (1995) 91-100.

[8] G. Kuncová, J. Zahradník, Gas holdup and bubble frequency in a bubble column reactor containing viscous saccharose solutions, Chem. Eng. Process. 34 (1995) 25-34.

[9] Y.T. Shah, B.G. Kelkar, S.P. Godbole, W.D. Deckwer, Design parameters estimations for bubble column reactors, AIChE J. 28 (1982) 353-380.

[10] Y.T. Shah, W.D. Deckwer, Hydrodynamics of bubble columns, in: N.P. Cheremisinoff, R. Gupta (Eds.), Handbook of Fluids in Motion, Ann Arber Science, Ann Arber, 1983, pp. 583-620.

[11] P.M. Wilkinson, A.P. Spek, L.L. van Dierendonck, Design parameters estimation for scale-up of high-pressure bubble columns, AIChE J. 38 (1992) 544-554.

[12] A. Schumpe, W.D. Deckwer, Viscous media in tower bioreactors: hydrodynamic characteristics and mass transfer properties, Bioprocess. Eng. 2 (1987) 79-94.

[13] J.J. Heijnen, K. van Riet, Mass transfer, mixing and heat transfer phenomena in low viscosity bubble column reactors, Chem. Eng. J. 28 (1984) B21-B42.

[14] S.H. Eissa, K. Schugerl, Holdup and backmixing investigation in cocurrent and countercurrent bubble columns, Chem. Eng. Sci. 30 (1975) 1251-1256.

[15] H.F. Bach, T. Pilhofer, Variation of gas hold-up in bubble columns with physical properties of liquids and operating parameters of columns, Ger. Chem. Eng. 1 (1978) 270-275.

[16] J. Zahradník, R. Peter, F. Kaštánek, The effect of liquid phase properties on gas holdup in bubble column reactors, Collect. Czech. Chem. Commun. 52 (1987) 335-347.

[17] S.J. Hwang, Y.L. Cheng, Gas holdup and liquid velocity in three-phase internal-loop airlift reactors, Chem. Eng. Sci. 52 (1997) 3949-3960.

[18] J. Philip, J.M. Proctor, K. Niranjan, J.F. Davidson, Gas hold-up and liquid circulation in internal loop reactors containing highly viscous Newtonian and non-Newtonian liquids, Chem. Eng. Sci. 45 (1990) 651-664.

[19] B.T. Kawalec-Pietrenko, Time-dependent gas hold-up and bubble size distributions in a gas-highly viscous liquid-solid system, Chem. Eng. J. 50 (1992) B29-B37. 
[20] B.G. Kelkar, Flow regime characteristics in cocurrent bubble column reactors, Chem. Eng. Commun. 41 (1986) 237-251.

[21] A. Schumpe, W.D. Deckwer, Gas holdups, specific interfacial areas and mass transfer coefficients of aerated CMC solutions in a bubble column, Ind. Eng. Chem. Process Des. Dev. 21 (1982) 706711.

[22] R. Krishna, P.M. Wilkinson, L.L. van Dierendonck, A model for gas holdup in bubble columns incorporating the influence of gas density on flow regime transitions, Chem. Eng. Sci. 46 (1991) 24912496.

[23] A.I. Shnip, R.V. Kolhatkar, D. Swamy, J.B. Joshi, Criteria for the transition from the homogeneous to the heterogeneous regime in two-dimensional bubble column reactors, Int. J. Multiphase Flow 18 (1992) 705-726.

[24] J.B. Joshi, N.S. Deshphande, M. Dinkar, D.V. Phanikumar, Hydrodynamic stability of multiphase reactors, Adv. Chem. Eng. 26 (2001) 1-130.
[25] M.C. Ruzicka, N.H. Thomas, Buoyancy-driven instability of bubbly layers: analogy with thermal convection, Int. J. Multiphase Flow 29 (2003) 249-270.

[26] J. Zahradník, F. Kaštánek, Gas holdup in uniformly aerated bubble column reactors, Chem. Eng. Commun. 3 (1979) 413-429.

[27] J. Zahradník, F. Kaštánek, J. Kratochvíl, Hydrodynamics and mass transfer in uniformly aerated bubble column reactors, Collect. Czech. Chem. Commun. 47 (1982) 262-276.

[28] A. Mersmann, Design and scale-up of bubble and spray columns, Ger. Chem. Eng. 1 (1978) 1-11.

[29] G.B. Wallis, One-dimensional Two-phase Flow, McGraw-Hill, New York, 1969.

[30] M.C. Ruzicka, J. Drahoš, M. Fialová, N.H. Thomas, Effect of bubble column dimensions on flow regime transition, Chem. Eng. Sci. 56 (2001) 6117-6124

[31] J.F. Richardson, W.N. Zaki, Sedimentation fluidization. Part I, Trans. Inst. Chem. Engrs. 32 (1954) 35-53. 